\title{
Large Scale PIV for confined fires.
}

\author{
E. Varea, B. Betting, C. Gobin, G. Godard, B. Patte-Rouland, B. Lecordier* \\ Normandie Univ, INSA Rouen, UNIROUEN, CNRS, CORIA, 76000 Rouen, France: \\ * Correspondent author: bertrand.lecordier@coria.fr \\ Keywords: Large scale PIV, PIV processing, Fire, Enclosure fire.
}

\section{Introduction}

Fire safety engineering, including knowledge of fire dynamics and fire-related hazards is crucial for securing people as well as rescue teams during interventions. One of the main critical aspects remains in determining the smoke dynamics at openings where fresh air and hot fumes mix. This particular phenomenon, encountered in many enclosures fires can reveal either wellventilated or under-ventilated fires. The response techniques of rescue teams are different depending on the ventilation status. Merci et al. (2016), Bengtsson et al. (2001) and Pretrel et al. (2012) have studied fire in enclosures that occur in oxygen-limited conditions. Generally, smoke dynamics are studied by using different devices or techniques. These include, among others, Pitot probes and bidirectional probes or McCaffrey probes, McCaffrey and Heskestad (1976). However, these probes are intrusive and potentially affecting the smoke dynamics. Moreover, only one-point data are evaluated. To overcome this difficulty, laser techniques such as PIV can be set up, see Tieszen et al. (2002), Hou et al. (1996) or Koched et al. (2012). PIV technique has already been used in case of well-ventilated and under-ventilated fires conditions. A natural extension of this technique remains in applying the PIV technique close to the outlet of the container in order to highlight exchanges between hot exhaust fumes and fresh incoming air.

The objectives of the paper remain threefold:

1. First, we propose a specific design of enclosure fire to ensure large scale PIV measurements inside the enclosure.

2. Second, the transition from ventilated to under ventilated fire conditions is evaluated

\section{Experimental Setup}

An experimental test bench is set-up to investigate the smoke dynamics characteristics of enclosure fires. Two maritime containers, one for the test cell, one for the measure and control cell are mounted perpendicularly. The standard size of a maritime container is $6 \mathrm{~m} \times 2.59 \mathrm{~m} \times 2.45 \mathrm{~m}$. These structures have emerged as training tools in rescue services. The volume of these containers is close to that of a room of a standard flat, which is approximately $35 \mathrm{~m}^{3}$. In the configuration, only one outlet (opposite to the fire) of $1 \mathrm{~m}^{2}$, is open. The fuel source consists of 36 propane burners with a surface area of $1 \mathrm{~m}^{2}$. Fire can reach $1 \mathrm{MW}$ with temperatures inside the container of $1000^{\circ} \mathrm{C}$.

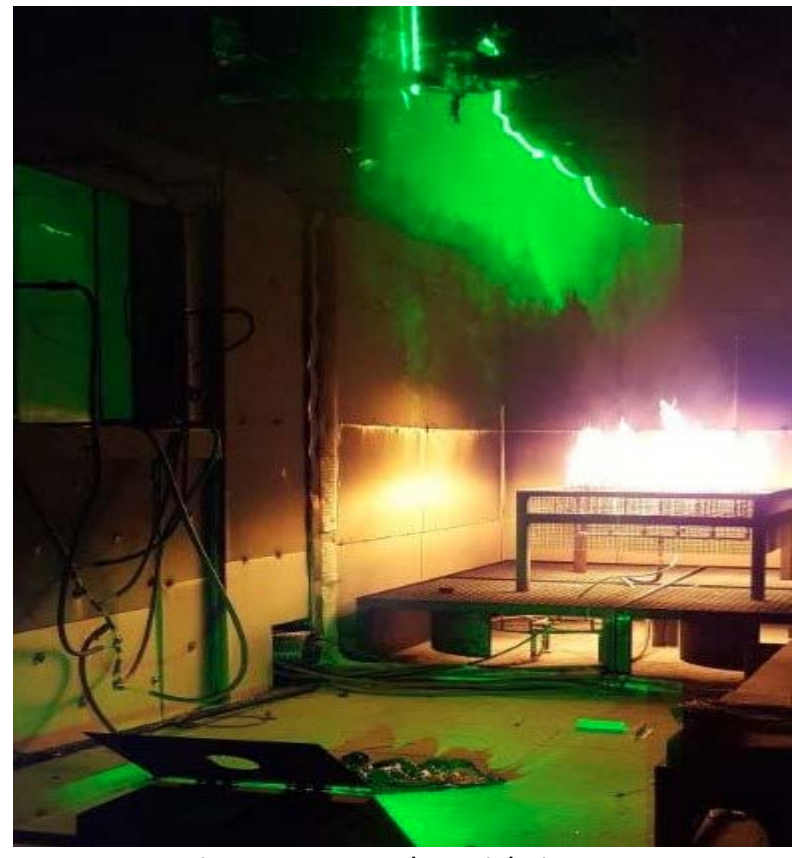

Fig. 1 : Laser and particle image
Large scale PIV is still a complex task and it represents a challenge in terms of seeding, imaging technique and PIV processing. Indeed, it exists a compromise between spatial resolution and field of view. Instantaneous, two-dimensional velocity measurements based on PIV processing of alumina particles are used. Alumina particles (A/2O3) - $5 \mu \mathrm{m}$ diameter) are chosen since they withstand high temperature due to combustion, see Narayanaswamy and Clemens (2013). These particles are injected through an in-house air supply corona, which is positioned below the burner. Particles are injected in a such way that the fresh air injection dynamics are not modified. As low as $10 \%$ of air to reach stoichiometric condition is used to feed the burner with particles seeded air. The flow is lightened by a Nd:Yag laser (Quantel QSmart, 2*400 $\mathrm{mJ} /$ pulse). A $-20 \mathrm{~mm}$ cylindrical lens produces a $0.5 \mathrm{~mm}$ thick laser sheet. Mie scattering from the particles is collected on 4 CCD (Charge-Coupled Device) cameras, (JAIRM4200, 12 bits, $2048 * 2048$ pix $^{2}$ ) mounted with $50 \mathrm{~mm}$ f/1.2 Zeiss lens. A $532 \mathrm{~nm}$ interferential filter reduces noise from ambient light sources. The optical arrangement yields a magnification of $5 \mathrm{pix} / \mathrm{mm}$. An illustration is given in Fig. 1, more details are available on Betting et al. (2019).

Data are recorded using Dantec Dynamics software. Raw images are post-processed with an in-house PIV software developed by Dr. B. Lecordier. The four individual PIV images are first combined into a single frame of around $4 \mathrm{kx} 4 \mathrm{k}$ using a reference grid used to determine the camera model. Images combination is made using polynomial camera model of $5^{\text {th }}$ order to compensate 
optical distortion and camera tilt. The relative images repositioning has been estimated to 0.1 pixels from analysis of overlapped visualization zones. A specific preprocessing to reduced correlation on identified structures resulting from local soot generation or interfaces due to non-seeded fresh air coming from the opening has been developed. Then PIV processing is performed using a cross-correlation technique between successive image pairs obtained after images recombination. The size of the PIV interrogation windows is $64 \mathrm{pix}^{2}$ with a $50 \%$ overlap. A maximum spatial resolution of $2.5 \mathrm{~cm}$ is reached. The time interval between two consecutive images is in the range of 1 to $2.5 \mathrm{~ms}$, depending on the powers and therefore flow velocity.

\section{Average vertical velocity profiles at the outlet}

Figure 2 shows the vertical component of the velocity profiles for $200 \mathrm{~kW}, 500 \mathrm{~kW}$ and $800 \mathrm{~kW}$ input powers. In order to get as close as possible to the outlet, the velocities are measured in the upper part of the laser sheet. Velocities are plotted along the $x$-axis. The colours red, blue and black represent the power of 200 kW, 500 kW and 800 kW, respectively. In Fig. 2, one can see that for the three cases, the first 0 to $500 \mathrm{~mm}$ reports positive velocities, which corresponds to hot smoke going out from the enclosure. Moreover, the higher is the power, the higher velocities are observed. This is linked to the increase of hot fumes that are released with increased powers. In the second part of the image -500 to $1000 \mathrm{~mm}$ - negative or positive velocities are observed. A fresh air return for $200 \mathrm{~kW}$ and $500 \mathrm{~kW}$ powers therefore exists. For the $800 \mathrm{~kW}$ power case, no fresh air return is observed. Following this observation, hot fumes leaving the volume interfere with the entry of fresh air, but in average only positive velocities are observed.

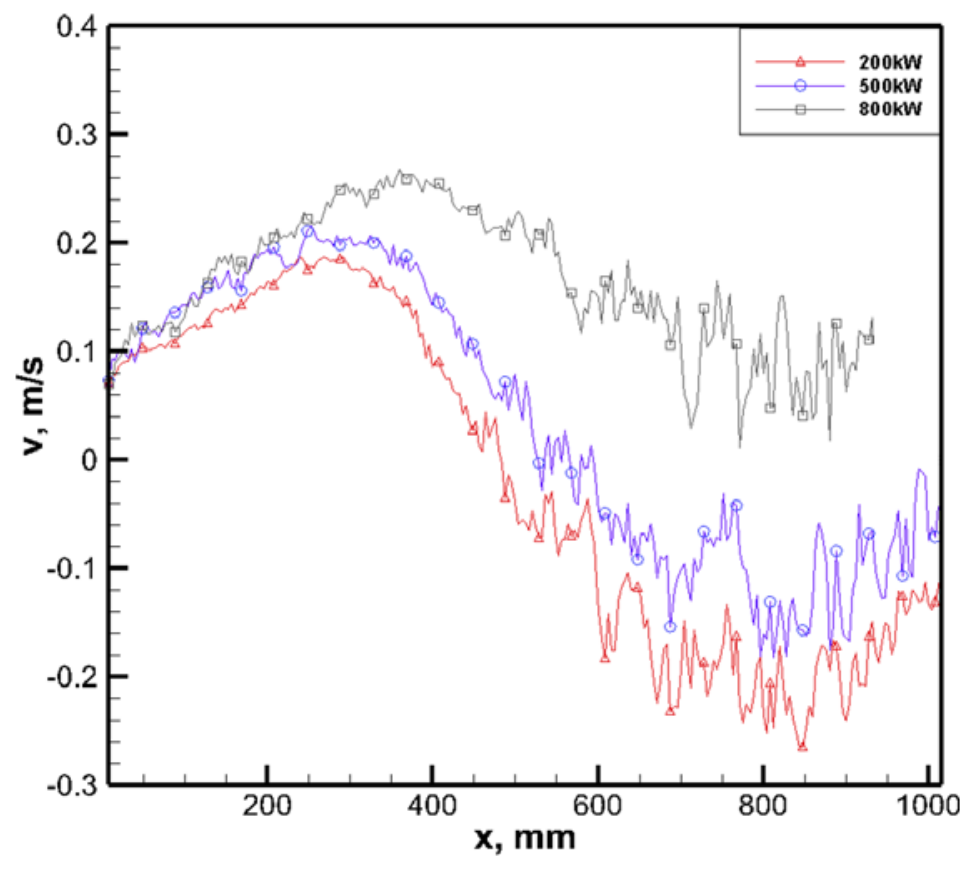

Fig. 2 Vertical velocity profiles at the outlet.

\section{Conclusion}

In this study, the flow topology of a confined fire is evaluated by Large Scale PIV measurements. Powers up to $1 \mathrm{MW}$ are reached.

An experimental setup composed of 4 PIV cameras and a high energy laser allows measurement of velocity fields at the exit of the container.

The velocity profiles of the vertical component along the $x$-axis are evaluated for both well-ventilated and under-ventilated conditions, below and above $500 \mathrm{~kW}$. For ventilated conditions, it is shown that a wellestablished structure where fresh air and hot fumes enter and exit the cell exists. However, for underventilated conditions, there is no significant fresh air inlet and only the air provided by the injection system facilitates combustion In conclusion, the existence of well-ventilated and under-ventilated conditions from velocity fields is demonstrated, resulting in a flowbased criterion that might make it easier the determination of ventilation status considering large scale confined fires.

\section{References}

1. B. Merci, T. Beji, Fluid mechanics aspects of fire and smoke dynamics in enclosures, CRC Press, 2016.

2. B. McCaffrey, G. Heskestad, A robust bidirectional low-velocity probe for flame and fire application, Combustion and Flame 26 (1976) $125-127$.

3. L. Bengtsson, Enclosure fire, Swedish Rescue Services Agency, Karlstad, Sweden, 2001.

4. H. Prétrel, W. L. Saux, L. Audouin, Pressure variations induced by a pool fire in a well-confined and force-ventilated compartment, Fire Safety Journal 52 (2012) $11-24$.

5. S. Tieszen, T. O'Hern, R. Schefer, E. Weckman, T. Blanchat, Experimental study of the flow field in and around a one meter diameter methane fire, Combustion and Flame 129 (4) (2002) $378-391$.
6. X. C. Hou, J. P. Gore, H. R. Baum, Measurements and prediction of air entrainment rates of pool fires, Vol. 26, 1996, pp. $1453-1459$.

7. A. Koched, H. Pretrel, L. Audouin, O. Vauquelin, F. Candelier, Application de la PIV sur un écoulement de fumée à un passage de porte induit par une source incendie, 13ième Congrès de Techniques Laser, CFTL, 2012.

8. V. Narayanaswamy and N. Clemens, Simultaneous lii and PIV measurements in the soot formation region of turbulent nonpremixed jet flames. Proceedings of the Combustion Institute, 34(1) :1455-1463, 2013

9. B. Betting, E. Varea, C. Gobin, G. Godard, B. Lecordier, B. Patte-Rouland, Experimental and numerical studies of smoke dynamics in a compartment fire. Fire Safety Jurnal, 2019, 108, pp.102855. 